\title{
SAVE YOUR WARDROBE
}

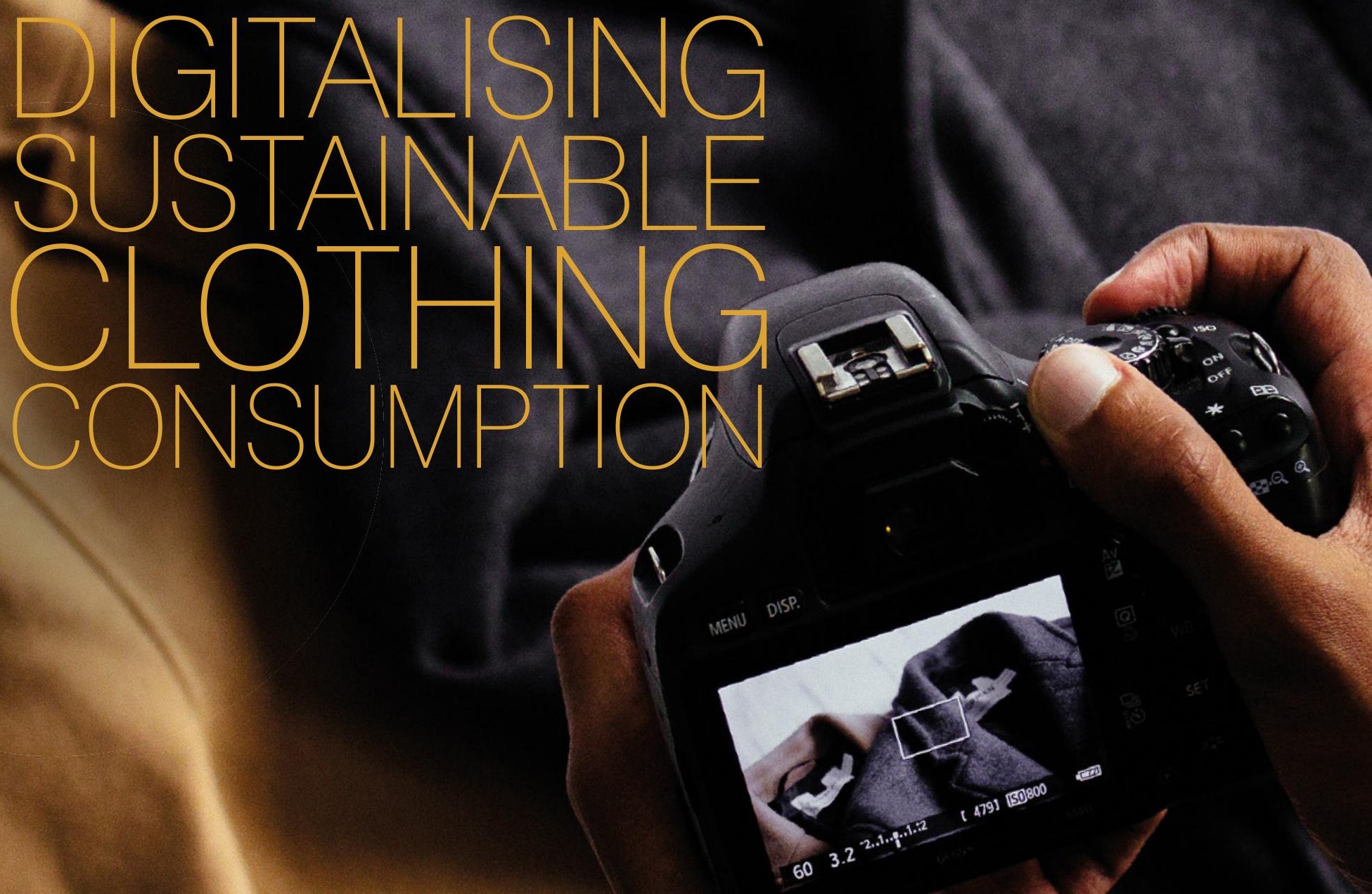




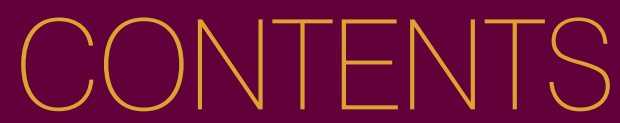

Authors

Save Your Wardrobe overview

4

Transitioning to more sustainable clothing consumption $\quad \mathbf{5}$

Introduction $\quad$ 6-7

Consumer experiences $\quad \mathbf{8 - 9}$

Disrupting patterns of overconsumption $\quad$ 10-13

$\begin{array}{lr}\text { A digital solution } & 14-20\end{array}$

$\begin{array}{ll}\text { References } & \mathbf{2 1}\end{array}$

Further information $\quad$ 22-23 


\section{AUTHORS}

This preliminary research examines the role of digitalisation in changing how consumers respond to, manage and maintain more sustainable approaches to clothing. It brings together the mission and vision of Save Your Wardrobe, with expert consumer researchers from University of Glasgow. Using a qualitative approach (in-depth consumer interviews and wardrobe audits) we explore existing clothing behaviours and how the Save Your Wardrobe (SYW) application (app) could be used as a digital wardrobe management solution.

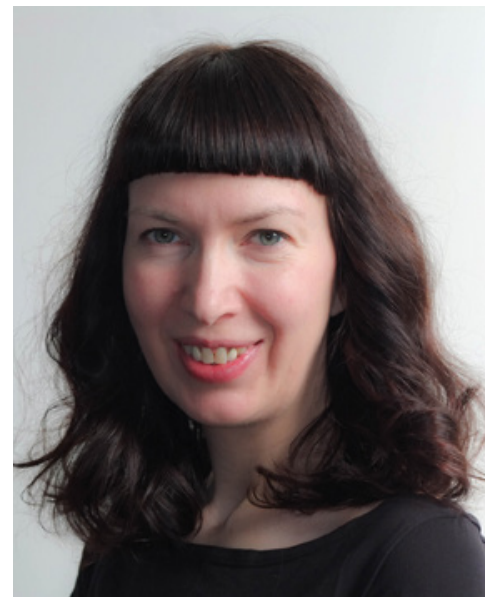

Prof Deirdre Shaw

Professor of Marketing and Consumer Research at University of Glasgow

Deirdre has researched the area of consumption ethics, including clothing and sustainability, throughout her career, publishing on the subject in a range of international journals (including British Journal of Management, Journal of Consumer Culture, Psychology and Marketing, Journal of Business Ethics, European Journal of Marketing, Business History, Sustainable Development), contributing to books and non-academic publications, giving invited talks, teaching and supervising $\mathrm{PhD}$ researchers in this area.

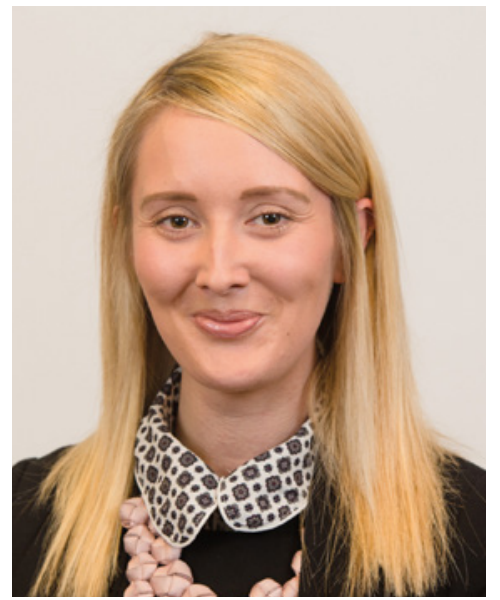

\section{Dr Kat Duffy}

Lecturer in Marketing at University of Glasgow

Kat researches the area of consumer culture with a particular interest in the digitalisation of consumption. Her research is published in international journals including Gender Work and Organisation, Journal of Marketing Management and Journal of Retailing and Consumer Services, alongside contributing to subject specific texts such as Bloomsbury Fashion Business Cases and Social Media Marketing. She is currently supervising PhD researchers in the area of clothing consumption and the Circular Economy. 


\section{SAVE YOUR WARDROBE}

\section{Save Your Wardrobe is a unique} mobile application that brings, for the first time, a complete view of someone's wardrobe (items, sizes, clothing value, behaviours and lifestyle), as well as, all the services needed around the clothing, unlocking more sustainable consumption behaviours every day. The company was founded in London in 2017 by CEO Hasna Kourda and her co-founder and CTO Mehdi Doghri.

The fashion industry is currently facing several social and environmental problems. Approximately 150 billion garments of clothing are produced every year and according to the Ellen McArthur foundation out of 53 million tons of textiles produced yearly, $78 \%$ are discarded.

Save Your Wardrobe offers to digitise the wardrobes of users and unlock the $80 \%$ of the clothes that are left unworn in their wardrobes. It provides insights and recommendations, saves time in selecting outfits, as well as creating an ecosystem of services, such as repairing, selling, donating or recycling clothes.
Save Your Wardrobe is a highlyengaging consumer app that helps save time and money and promotes sustainable post-purchase consumer behaviour. It is brand agnostic and customer centric, creating a new category in the market, which will change consumer behaviours in fashion and retail. By using artificial intelligence at each stage, the journey of the user is optimised and improved. The app offers personalised, unique recommendations and insights about the users' wardrobe performance that keep them highly-engaged.

\section{through your favourite online retailer}

through your email

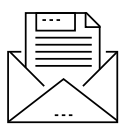

personal recommendations<smiles>C1=CCCCC1</smiles>

your personal virtual fitting room

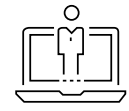

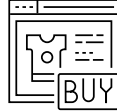<smiles>[C]1C2CC3CC1CC(C2)C3</smiles>

by scanning your actual wardrobe

newsletter

curator
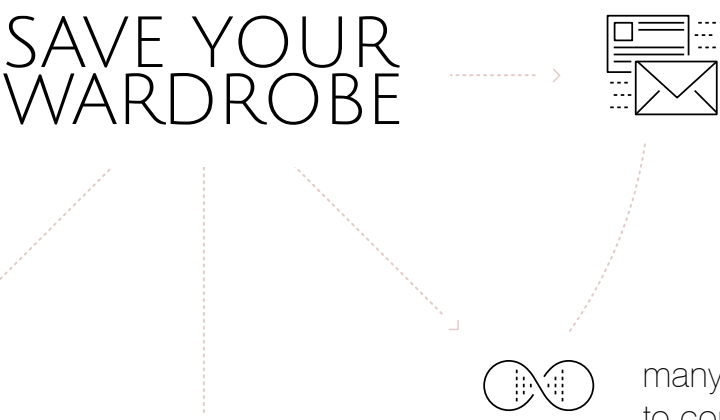

many more

to come

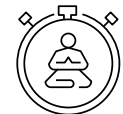




\section{HOW DO WE MAKE THE TRANSITION TO A MORE SUSTAINABLE WAY OF CONSUMING CLOTHES?}

\section{Worldwide clothing is important} as evidenced by a global garment industry valued at around US \$1.7 trillion and employing approximately 75 million people (WRAP 2015) There are, however, significant environmental costs from resource inputs, manufacture, use and disposal of clothing. In the UK, clothing has the fourth largest environmental impact after housing, transport and food and more than half of fast-fashion items are thrown away in less than a year (McKinsey 2018). The UK Parliament Environmental Audit Committee
(2019) highlight the social and environmental costs of our clothes, the impact of textile waste and the need for alternative fashion business models. The findings emphasise an aim to end the era of throwaway fashion in the UK, with a focus on retailer extended product responsibility and an emphasis on consumers repairing, re-wearing, reusing and renting as preferable to recycling or discarding clothing.

The role of the consumer is, thus, key but becoming a sustainable clothing consumer is not an easy task. The complexity of environmental and social issues through raw materials, production, consumption and disposal are peppered with uncertainties and contradictions. Individual consumers are often left disillusioned and ill prepared to broach the problems encountered. This makes it important to understand the opportunities provided by digitalisation in supporting more sustainable approaches to consumption.

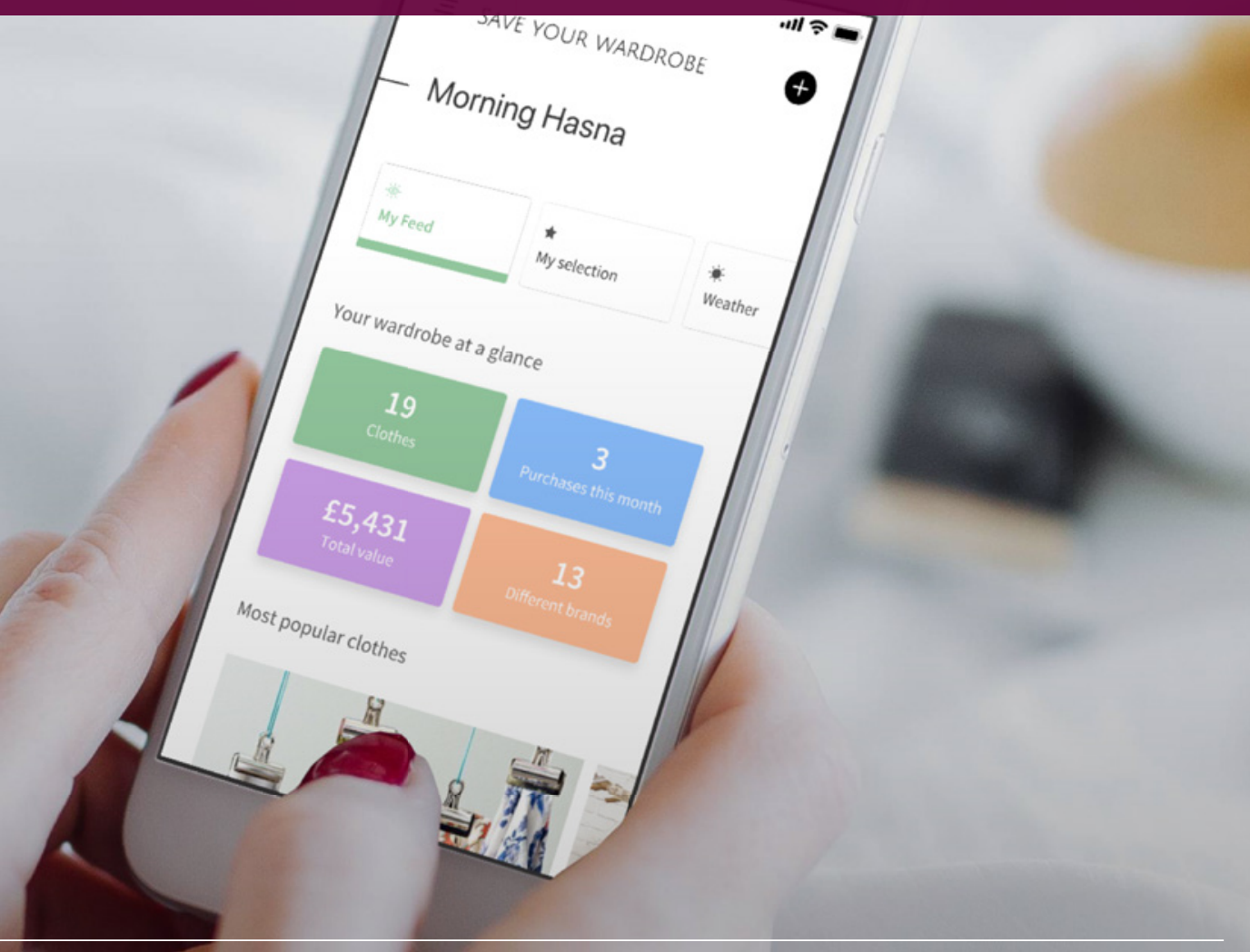




\section{Overconsumption by consumers}

is a principle challenge to sustainability, thus, approaches that can foreground a sustained shift in consumer behaviour are critical. Mindfulness has been receiving attention in research on sustainable consumption to disrupt automatic thinking, enhance awareness and foster prosocial values and behaviours (e.g., Stanszus et al., 2017). There have also been calls for consumers and businesses to be more mindful in their approaches to consumption and in their market offerings (e.g., Sheth et al., 2011). While a need for consumer behaviour change is clearly identified as important for systemic sustained change, little insight is provided as to how this mindful shift can be facilitated.

Digitalisation has provided consumers with readily available mobile mindfulness apps to help them prioritise taking time out of their busy lives and focus on reconnecting with themselves. Would these kind of tools work within a clothing context to impact more mindful and sustainable behaviours? Digitalisation offers consumers new ways of 'managing, calculating, communicating and evaluating environmental and ethical information' (Fuentes and Sorum,
2019). Digital tools offer assistance to concerned consumers in terms of advice on what to buy, where to buy, who to boycott and buycott, etc. While such tools have the potential to facilitate more sustainable behaviours, it is unclear exactly how they can achieve this in practice. Further, to-date there has been no consideration of digital tools that seek to draw on the dual benefits of mindfulness and sustainability in a clothing consumption context.

As journalist Lucy Siegle announced at the start of 2018, "everyone should embrace a mindful wardrobe" and this sentiment was further highlighted in the Elle sustainability issue, to "consider a more mindful way to shop" (Elle, 2018). While there is academic research suggesting a positive relationship between mindfulness and sustainable consumption (e.g., Amel et al., 2009; Brown and Kasser, 2005), such work is subject to criticism. These approaches do not move beyond the self to compassion for others and the planet and a questioning of current values and ideologies necessary to move towards more sustainable behaviours.

This preliminary research examines the role of digitalisation in changing how consumers respond to, manage and maintain more sustainable approaches to clothing consumption. Employing a qualitative approach we explore existing clothing behaviours and how the SYW app could be used as a digital wardrobe management solution.
SYW aim to bring a new experience to consumers and help them make the most of their wardrobe and extend the life of garments. This collaborative preliminary research uses a qualitative approach as a way of gaining an understanding of current consumer clothing behaviours and engage consumers in the use of the SYW app as a way of considering more sustainable and mindful approaches. Based on twenty in-depth interviews and wardrobe audits with SYW beta testers ${ }^{1}$, we took an open iterative approach to the analysis of the interviews in line with standard qualitative techniques.

The report is organised into three sections detailing our findings. The first section focuses on consumer experiences of clothing consumption, the second on how overconsumption is being disrupted, and thirdly on the SYW app as a digital solution. For each section we offer recommendations.

\section{Dr Kat Duffy \\ Prof Deirdre Shaw}

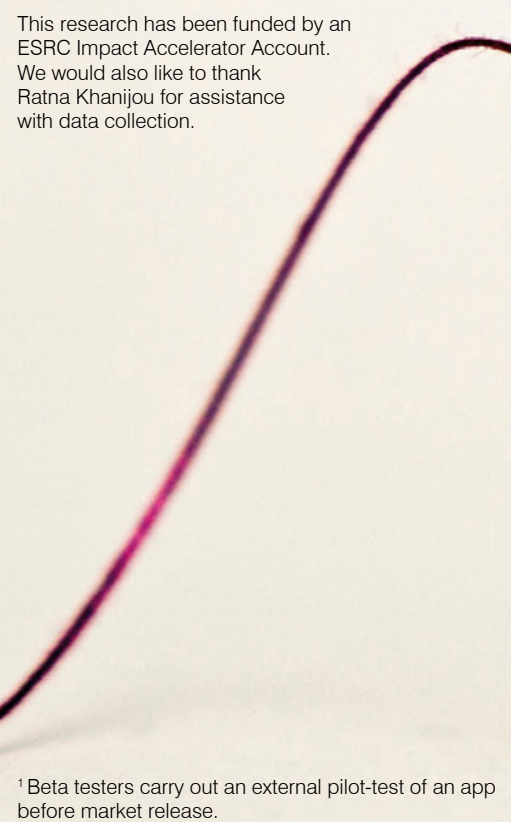


This preliminary research examines the role of digitalisation in changing how consumers respond to, manage and maintain more sustainable approaches to clothing consumption. Employing a qualitative approach we explore existing clothing behaviours and how the SYW app could be used as a digital wardrobe management solution. 


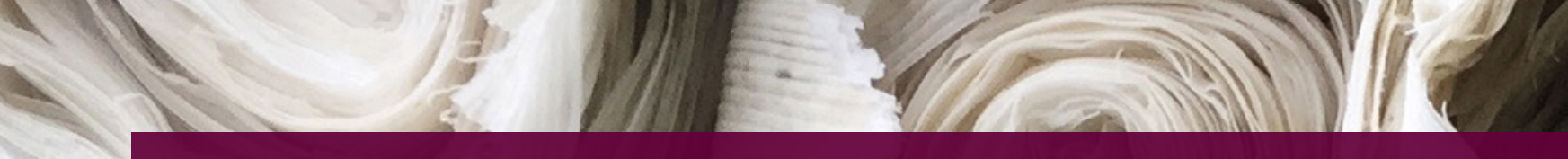

\section{CONSUMER EXPERIENCES}

\subsection{The clothing problem}

The consumers in our research communicated the oftenoverwhelming negative feelings they had when thinking about their own clothing behaviours. Feelings of anxiety and dissatisfaction with current approaches were highlighted - one consumer described feeling like they were "drowning in clothes." Many shared feelings of being overwhelmed and burdened by mounting masses of clothing, citing a lack of space and subsequent storage issues.

Consumers described feeling out of control with their buying, but unsure what to do differently. Fuelled by market forces, such as, social media, advertising and influencers, the gaze of brands was hard to avoid. They are buying clothing to reward when they had a good day, but also buying clothing to soothe when they had a bad day. The emotionally charged nature of buying clothing; the wanting, purchasing, wearing, hoarding and eventual disposal, was a cycle that was hard to escape.

There was generally an awareness of over-consumption and an aspiration to become more conscious of their clothing consumption but a feeling of limited agency to change what had become an entrenched habit:

"I do have a lot of clothes because I get bored of them quite easily, and when I look at my wardrobe I never find what I need. I end up having a lot of stuff that I do not need, or I do not like anymore, and it's quite frustrating"

"It feels like we get sucked into this unthinkably and unknowingly this trend to buy more and shop more and look great all the time and just this never-ending pull of consumerism and I don't like that."

\subsection{Consumer anxieties}

The abundance of clothing choice and accessibility that facilitates overconsumption comes at a price, not just for our environment but also for consumers who are increasingly overwhelmed and anxious as they seek to make the 'right' choice, present the desired 'right' identity and expend the time, energy and financial resources to support these activities:

"It is just that for me personally I would feel happier if I felt like I was making really thoughtful decisions and they weren't coming from a place of anxiety or a place of feeling constantly like there is some new gap in my wardrobe that I have to fill"

"I think a lot about reducing the eco footprint of my lifestyle. And I think clothing is like one area where I get frustrated because I don't think feel like my stated values line up with my behaviour if that makes any sense? I feel like we should just consume less, but then I can get anxious and stressed out and feel like I need something and those two things are incompatible to each other"

\section{SUMMARY}

Consumption of clothing is fuelling anxiety. That anxiety permeates consumer society is not new, indeed, this is the foundation of successful consumerism (Jackson, 2019). Here we see consumers starting to be more aware of the resulting anxiety, social pressures and carelessness they feel they derive from their current clothing consumption.

\section{RECOMMENDATION}

Clothing consumption solution that offers consumers the opportunity and assistance to manage their current collection of clothing. This should facilitate agency and knowledge around what they have, what they need and use and recommendations for moving out what is no longer required. This should be provided in a contained, user friendly wardrobe management system.
"I think a lot about reducing the eco footprint of my lifestyle." 


\section{Table 1: Examples of Consumer Experiences}

\section{INSIGHT}

\section{1 the clothing problem}

Consumers identify and problematise their clothing consumption and wider associated issues

\section{INTERVIEW DATA TO SUPPORT}

- "I feel like fast fashion, is just trying to sell, sell, sell. Sometimes I feel like it is too much"

- "I love clothes. I buy clothes at least every month."

- "I'm an online smash and grab person now."

- "It feels like I am constantly accumulating new clothes like not necessarily by design but through interacting with life. Like I feel like there is constantly like something on offer and eventually you are like, 'Oh I want that.'”'

- "I like the shopping experience more than the clothes themselves, so sometimes when I do not feel good or when l'm bored I just go and do some shopping, just to look at what they have, and then if something is nice I buy it. So, let's say, $60-70 \%$ of my purchases are emotional purchases rather than something that I really, really need."

- "We've spent quite a long time thinking about where food has come from, 'Is it organic, is it free range?' and that's kind of part of our general, it's an automatic thought process in a way to know where food has come from, 'Have these strawberries come from England, have they been flown in from the Canaries?' So I think we've thought about food for a long time but I think we're only now really starting to think about fashion and the steps that it goes through."

- "I mean I recently went through a kind of, I tried to take out from my closet stuff that I had never worn and I kind of do a closet clean up. And I found like three things that I had ordered online and they were still wrapped in their plastic bag that I had never worn so that I bought two years ago and I literally never wore."

- "So for example I never think of the environmental aspect. I do that for food but I don't do that in terms of the clothes."

- "It's just the consumption thing that we have in our type of society, that we need to buy, to buy, to buy, to buy. At some point we just need to be a little bit responsible about what we do, because we are maybe in this half of the world where we can buy and we abuse the rest of the world to create all these things for us to buy. I think at some point, if everyone tried to make an effort, that can rebalance everything."

- "The worst is when I find myself saying I need something. I need. But we don't really need anything. Yes intellectually I know that but sometimes when I get stressed out especially if I am feeling insecure, yes that is part of why I made the resolution to not order clothes online. Because if I am feeling really insecure sometimes I can find I buy all this stuff I don't need because it makes me feel better for a little while. Because we can buy our way to feeling better, which of course doesn't make any sense!"

- "So I buy a fashion piece which looks nicer, but then it's not warm enough and so there's a lot of money wastage in my wardrobe."

- This is a big issue for me that I struggle with, to be honest, because I end up having a lot of clothing inventory, and taking care of everything is just like a big job for me and I do not have time to do it."

- My wardrobe does not make me happy right now because it's messy; it's in a mess. I don't have enough space in my wardrobe, clothes are tucked up, and I have trouble finding the right pieces."

- "I don't feel very comfortable shopping. When I go into a store I don't like it when the staff come up and ask if they can help you with something. I like doing what I want to do and getting it done. It's not an experience that makes me feel very confident. It makes me feel a bit vulnerable, shopping generally." 


\section{DISRUPTING PATTERNS OF OVERCONSUMPTION}

\subsection{Reflecting on the impact}

Consumers spoke of loving clothes but feeling conflicted about aligning a love of clothing with sustainability principles:

\section{"I slowly started being a bit more} thoughtful because it is a bit like you should keep your wardrobe the same way you keep your house. It should be neat and it should be respectful and have values behind it rather than just stuffing it with pieces that you may or may not use."

Many consumers said they buy too much and too often and they have either started changing their consumption patterns or change is one of their personal goals (e.g., to buy less frequently/more expensive but better quality/brands that have an ethical ethos). For many, sustainability is linked to the production process with awareness of the consequences of their consumption heightened through media attention and activism campaigns, such as, Fashion Revolution. All are aware of the issues associated with clothing consumption, but many have not considered this for the entirety of the consumption cycle:
"Obviously people are dying, women are being treated very badly, children are working in the cotton industry and the level of pollution is something that I wasn't really aware of. I was like, 'I can't change the world but I can do things that I can do. So I can change my behaviours, I can change the things that I do, I can talk about it to other people and, as much as I can, make anybody else aware and make them start to think about it."'

"I like shopping for clothes but I was always conscious that the clothes l'd buy have an impact on someone somewhere."

\subsection{Micro-resistance}

Some consumers developed selfregulation strategies to manage their clothing consumption. This included putting items in the cart when shopping online and leaving them there for a self-specified period of time. In doing so consumers sought a more conscious and mindful approach to shopping, rather than satisfying an initial curiosity or purchasing urge. This self-imposed time lapse allowed consumers to reframe their 'want' into a 'need' and less frequently moved straight into a purchase:

"If I buy on Asos or similar I have a next day rule. So if I fill up a basket I will come back to it the next day. I will wait. Unless it is super urgent, which I doubt it is, I will pick all the things I want and then come back to this tomorrow and say, 'I don't want that, I don't need that.' So yes that is my approach in terms of consideration."

We also see consumers switching to vintage or second-hand shopping in attempts to reduce their environmental impact and break with the consumerism norms of continually buying new:

"I just thought there's a way I can feel better about my clothes if I shop more intelligently. Living in London, you're surrounded by overwhelming consumerism all the time, so it felt like a sort of fight back against that consumerism, to buy second hand or vintage because you're not adding to it. I mean I'm fuelling it in a different way I suppose, but I'm not contributing to the churn of new stock every week. It's sort of overwhelming. So it was like a push back against all of that."

$$
\text { to }
$$




\section{"I love buying clothes. I like shopping, but I also try to do it with a kind of thought about the environmental or the kind of impact that my shopping has."}

"I love buying clothes. I like shopping, but I also try to do it with a kind of thought about the environmental or the kind of impact that my shopping has. So l'd say over the past two years I mostly buy second hand or vintage and if I'm going to buy something new, I will research the brand first and buy from an ethical brand that doesn't produce things in sweatshops and all that sort of stuff, which is another reason I shop new less often because that just costs more money to do it like that."

\subsection{Care and repair}

Care and repair varied across consumers. Aftercare of garments varied from looking at individual labels and adjusting practices accordingly, to washing everything after every wear and others who find the labels unhelpful or unclear and, therefore, treated all garments similarly:

\section{"So l'll always balance up if} something needs to be dry-cleaned against what l'm going to spend on it because then dry-cleaning is an additional cost each time it needs to be cleaned."

"Most of my clothes I wash in my washing machine. I can't remember myself doing dry-cleaning though. I do something else with my coats, but when they are just worn out I just throw them away and that's it; I don't bring them to dry-cleaning services."

Some consumers focused on being able to learn skills that they did not previously have to help facilitate repair of garments. This is viewed as cost saving but also as a way to personalise and rejuvenate the item:

"I think a lot of the clothes that I've got now, I really love them. And if they are one-off things, so if they are vintage, once they're gone they're gone, you know, I can't get them back, so l'd rather see if I can repair them or do something with them. And also I just think it's economical; I don't want to just throw things away if I can repair it, change it into something else, make it into something new."

Many spoke of actively de-cluttering their wardrobe and giving away to charity. This often had a designated timeframe attached to it (such as, 6 months of non-wear seen as a sign to give away; reflecting on an item for several weeks before deciding to give it away). Consumers described clearing out as seasons change and moving garments around the home. This provided an opportunity to question the use value and potential of items. Parting with garments, however, was on the whole a considered process, often with intermediate stages before the items made their way out of the home; and, in this example, to the charity shop:

"I always do a two-step and kind of go, 'Right, l'm going to put it over there', if I do kind of think it's come back into my consciousness I kind of put it over there but if I still don't want to wear it, don't need to wear it, then I'll get rid of it."

\begin{abstract}
SUMMARY
Within this disruption of patterns of (over)consumption, we see consumers overburdened within their consumption and making the space and time to sense check and develop strategies to approach their usage and buying. We note consumers using language around mindfulness to make sense of their consumption and start to question previously taken for granted practices. This capacity for change, however, is diminished as consumers feel they are limited in their power to make more holistic sustained changes.
\end{abstract}

\section{RECOMMENDATION}

A platform that offers consumers a space where they can mindfully explore alternative approaches to clothing purchase, use, maintenance and disposal. Where knowledge and practices can be shared which support new and sustained clothing routines. 


\section{Table 2: Disrupting patterns of overconsumption}

\section{INSIGHT}

2.1 Reflecting on the impact Identification of issues within the current clothing consumption behaviours. Starting to sensemake around their own behaviours and identify areas for change.

\section{INTERVIEW DATA TO SUPPORT}

- "I love clothes first. I would say that I buy clothes every month. I tend to think about it a little bit more now because it's more something that everyone is talking about, but I know from a consumer point of view, my point of view and my budget, it can be sometimes hard to mix both"

- "There was no one lightbulb moment or no one individual, you know, factor. I just was conscious of my own consumerism and it feels like we get sucked into this unthinkably and unknowingly, this trend to buy more and shop more and look great all the time and just this never ending pull of consumerism and I don't like that. I like to be more in control about that, so I chose a different shopping path."

- "In theory I think I could never shop again for the next 10 years and I would still be very happy with what's in my wardrobe. I don't need to shop anymore. I have enough clothes to wear for a long time. But I love shopping and I love buying clothes and I love finding new little treasures. It makes me really happy. So although I'm trying to change the way I shop and do it in a better way."

- "I would like brands to become more sustainable so it is not like the extra add on thing but that is the general thing that everyone produces fair trade and sustainable fabrics."

- "I would like to change it all and, you know like you're starting from zero and maybe have a different approach to clothing. Instead of buying 100 pieces, just buy 20 pieces which I really need and which are of very good quality, good brands, quite expensive; rationalise, a little bit, my wardrobe."

\subsection{Micro-resistances}

Consumers using different mechanisms such as charity shopping and donation, vintage or second-hand shopping to 'push back' against the consumer mainstream norm. Taking out the immediacy of online shopping.

\subsection{Care and repair}

Developing strategies to approach maintenance of clothing, repair and moving clothes on through resale, charity donation, decluttering.
- "The cost of finding things in charity shops, they're a lot more aware so you still have to be prepared to pay a bit more. I think there's also that element of finding something that's kind of original and different from other people"

- "You should be able to give away your clothes and give away something you don't need, and making sure what you have in your wardrobe is what you need and what you need to wear."

- "I feel like first of all it is too easy, like I kind of order things without really thinking about it."

- "Through thinking more about your purchases and asking yourself the question why do you need those? Through that, you can end up saying I have 19 tops. They are the same. I think I need to give somebody else this top. It needs a new home, you can sell them through Depop or you can give it away as a gift or charity or something."

- "So l'll always balance up if something needs to be dry-cleaned against what l'm going to spend on it because then dry-cleaning is an additional cost each time it needs to be cleaned."

- "I repair as many clothes as I can. So about eight months ago I learnt embroidery so I can darn things, and also if it's got a mark on it or something else l've just been embroidering so doing invisible mending. And l've been offering that service to my friends as well so l've been taking their clothes in and doing embroidery. And I can take things up myself, I can sew, so I can do things like that." 
- "So kind of one of three things. I'll either, can I re-inject life back into it in any way, and if yes, then great and if no, well where else can it go to? Can I sell it on eBay or Depop or whatever it is? Would someone else...? Am I just sick of it but would someone else still like to wear it? If it's just I've lost all interest in it but it's still okay, I would give it to charity, or if it's really something that I think is kind of beyond repair then I will put it in a clothes bank, a textile bin. Like if it's got a hole, a T shirt with a hole in it that I can't repair or whatever is, it's just gone, then I put it in a textile bin."

- "I have a rule in my wardrobe. If I stop wearing things and it has been around for more than a year, I give it away to charity or give it to my friends, or sell it online if it's an expensive item."

- "Then if I really don't wear them for a year and a half, or two years, I decide to give away the clothes."

- "You kind of feel as though you're dumping stuff in a way, you know, and they might make a bit of money out of it, they might not, and then if it's not it just gets kind of torn up and made into insulation." 


\section{A DIGITAL SOLUTION}

\subsection{Desire to save time and quantify behaviour}

In sharing the SYW app with consumers, practical priorities, such as, streamlining their wardrobe management, time saving and efficiency were prominent. There was a desire for the app to function as an awareness aid in helping them to be more aware of what is in their wardrobe at point of purchase. The app was considered to have important potential as a personal stylist, recommending daily outfits and removing the time consuming 'thinking' process.

\section{Consumers considered the app} relative to other familiar digital solutions, such as Fitbits. The opportunity to sense make and quantify, especially with a monetary value $^{2}$ attached to it, was seen as hugely appealing. Such insights into their own behaviour, including, times worn or outfit histories, was viewed as providing the knowledge essential to deriving value from their garments.

A digitised wardrobe was viewed as a means to think about the wardrobe as a whole, rather than on the basis of individual items.

Through the capability and capacity to gain insight into their wardrobe inventory, consumers reflected that they could be more strategic about purchasing, use and disposal:

"Whether I buy things once a week, once a fortnight, once a month and because that would be able to quantify that would be interesting. When you can assign data to something, you can change it or at least measure it, so that bit's interesting."

\subsection{Control and empowerment}

Consumers wanted to feel more in control of their purchasing choices. SYW was viewed as an effective aid to the planning, use and disposal of clothing with full knowledge of their current wardrobe inventory. Compared to other digital tools, the app dashboard functionality would allow consumers to curate their outfits, style and wider wardrobe management:

"If you have an app that says you know, you already own seven pairs of jeans, as you're standing there considering buying your eighth pair of jeans, and if you have an app that really helps inspire you about the clothes you already have, then I would hope that there would be some corresponding reduction in the amount that we all buy."
${ }^{2}$ If the user decides to login with their email address and provides access, their online receipts are uploaded to their wardrobe profile. SYW calculate the value of the content of their wardrobe based on the price of the items found in the receipts. SYW use a third party algorithm that estimates the depreciation rate and the value of the wardrobe items on secondary markets. This starts as a basic overview of the total wardrobe and will evolve in the future taking into account alteration, repairs, customisation etc.

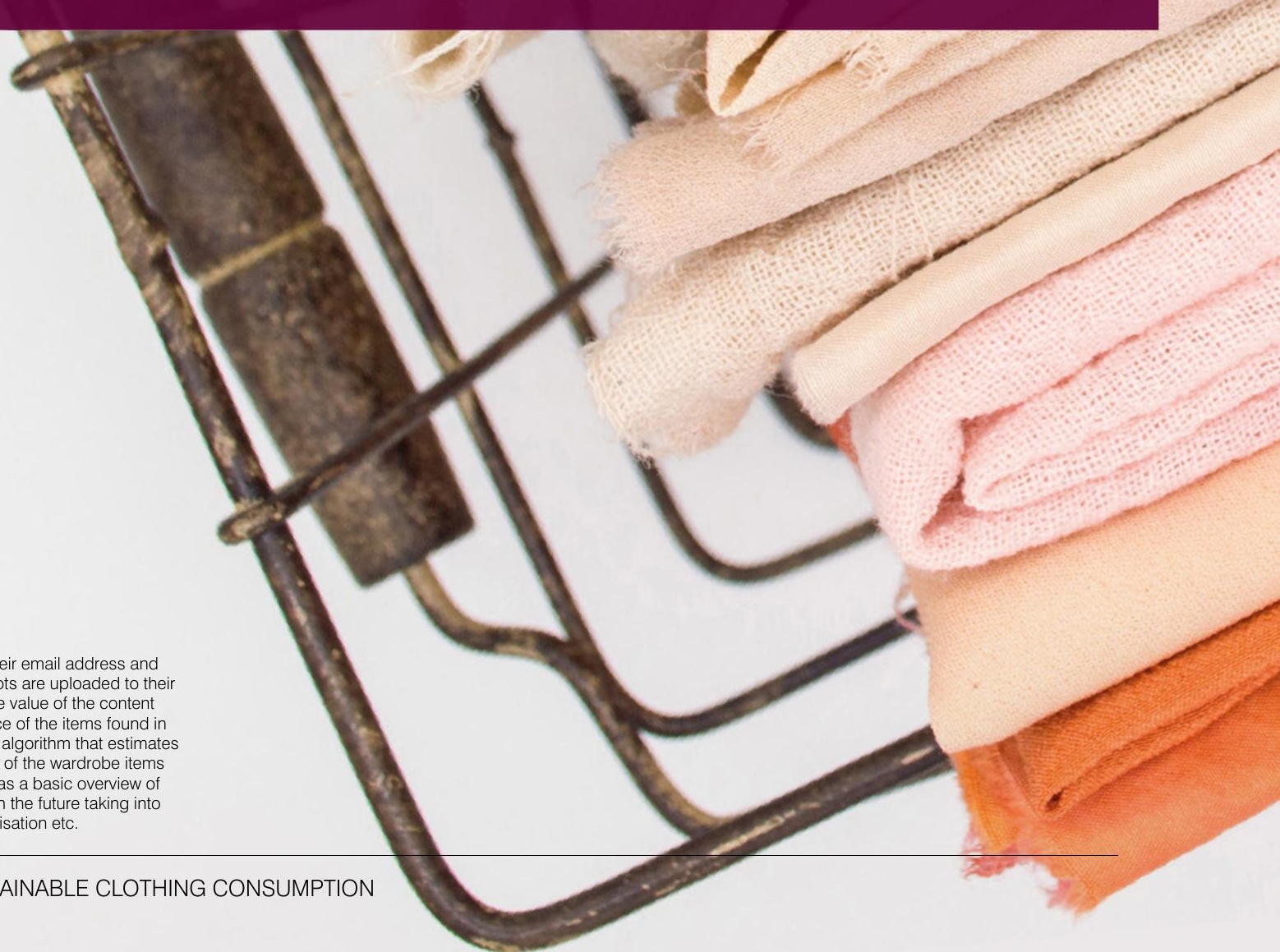





\subsection{A holistic solution}

In addition to wardrobe quantification and value demonstration, consumers were excited by the opportunities linked to related services (such as, dry cleaning, repairs, re-sale and alteration). Consumers viewed the SYW app as offering a holistic, 360-degree consumer centric solution, with a focus on the integration of core services of inventory management and additional services, such as, the opportunity to sell, mend and maintain.

We see an appetite for the SYW app particularly among consumers who are used to digital mechanisms and interventions in their lives to organise and streamline behaviours. The integration with their existing digital self and ability to link to calendars and events, helping them to 'frame their lives' is seen as advantageous. Through the machine based learning built into the app, consumers hope the app will deliver personalised solutions, aid their wardrobe curation and will gain understanding of their patterns of behaviours, styles and tastes:

"I love an app that kind of frames your life... just like having everything in one place, in control of everything that's happening in my life."

\subsection{A mindset shift - becoming a mindful consumer}

Throughout the research consumers referred to their gradual mindset shift in relation to their clothing behaviours. This was related to the growing prominence of sustainability in clothing consumption, with a vocabulary accessible through use in the media and social media shifts around deriving joy in clothing (the Marie Kondo effect), the toxicity of the fashion industry (BBC and Stacey Dooley's Fashion's Dirty Secrets), to the House of Commons Environment Audit committee report (Fixing Fashion: clothing, consumption and sustainability, 2019). For some the potential shift to more mindful consumption was viewed with excitement, while others were more reticent about the time commitment and information necessary to overhaul their behaviours. For the former group, the mindfulness and sustainability approach of the SYW app is an important emphasis. Most say they want to consume more sustainably (buying less, buying better quality, buying brands that have ethical ethos). Here we see the mindfulness ethos linked closely to considerations of taking time and being thoughtful over consumption choices and care/ wear of clothing to extend the life of the garment. With more hesitant consumers, the investment of time into the app, of logging existing wardrobe items and of the learning curve necessary are barriers which would need appropriate management by SYW to help overcome. This group also tended to feel overwhelmed by information and distrustful of sustainability claims:

"Being aware of yourself; being aware of your environment; of your surroundings; of other people; of your impact on this earth, on society."

"Mindfulness means to me that I am more aware and more conscious of what I wear and again this is where sustainability and ethical approaches come into play."

\section{SUMMARY}

We find that the SYW app has the potential to both enable and motivate consumers through empowering them to feel in control of their wardrobe management. We see consumers problematising their clothing behaviours and wanting more information to quantify their existing practices and make changes. The SYW data is essential to facilitate that process. The app provides the opportunity to amplify the connection users feel with their clothing. Such awareness has strong potential to support consumers in questioning current behaviours and supporting more sustainable ones.

\section{RECOMMENDATION}

A holistic wardrobe management solution that supports engagement in sustainable action. A space where consumers feel in control of their own actions in line with principles of sustainability and supported in reframing their behaviours. 


\section{Table 3: A digital solution}

\section{INSIGHT}

\subsection{The desire to save time} and quantify behaviour Consumers identify key benefits to using the SYW app and how it would allow for a greater understanding of their wardrobe behaviours through quantification.

\section{INTERVIEW DATA TO SUPPORT}

- "From standing there in front of my wardrobe going 'oh my god' what shall I wear today, instead to me it would be a flick through the app and say shall I wear that. It feels like it could be a faster decision making process and, therefore, save time aimlessly standing there. I think it's interesting because in essence, a lot of the technology that we use these days isn't actually doing anything revolutionarily different, it's just making life a little bit easier."

- "The basic function that I understand is you can digitise your wardrobe and then it'll help you put together outfits and, therefore, ultimately help you wear more of the clothes that you own already. So if I have an interview or a meeting coming up, l'm running late and my son isn't even dressed yet and we need to leave the house in 10 minutes or half an hour, whatever it is, I could use the app and it could go well here are three different outfit suggestions that you could wear from the clothes that are in your wardrobe."

- "I wish I could automate choosing clothes, it would reduce my time in the morning, the times that I allocate to this every morning. It will free some brain bandwidth for me to do something else more important."

- "The app will make you more aware of what you already have in your closet and how you could combine those things. And how to look quite stylish with those things you already have."

- "The other aspect that I suppose is a new addition to it is there must be a way to track or record or look in the app, such as, when I started I was wearing $20 \%$ of my wardrobe and now I'm wearing $75 \%$ of my wardrobe. A bit like Fitbit, so I suppose having that little bit of data for me is an interesting aspect of it because that's the part of the newness that the technology brings to the idea, is being able to quantify. Oh yeah look, you wore this much of your wardrobe and saved this much time, not that they could tell me. I think I would just know I saved time but the quantifying bit would be about how you're getting better value from your wardrobe."

- "You know one of the rewards of technology is that it rewards you in some way, shape or form, to me that would be a reward to go 'hey, did you know this month you wore $15 \%$ more of your wardrobe than you did last month'."

- "If laundry is built into it, I think that is part of the solution and it could almost become a regular admin thing to do. Just like you know you can order food boxes home and you do it once a week and it's done."

- "I think part of the culture I grew up in was very much like you can optimise things and there is a better way of doing things and you should be thoughtful about your life and also gathering data is also good."

- "For me the only worry would be the start-up cost of it because I would have to digitalise everything I own already."

- "The purpose is on one hand to find items, when you go shopping that you find items that match your current wardrobe. On the other hand it is to have a complete overview of what your wardrobe includes. Because sometimes you are looking for a black top and then you come home with a black top and you see there are already two black tops"

- "I think I like the total value thing, because it enables me to put a price tag on my clothing inventory, so it makes me feel... it raises my awareness about the amount of money I spend and then it makes me want to be more responsible when it comes to spending."

- "I think I already am mindful about my shopping choices, and so I think it would help me in terms of the inspiration and the making the most of what I already have." 
"I think we should have a mindful approach to purchasing, consuming and disposing of clothing."

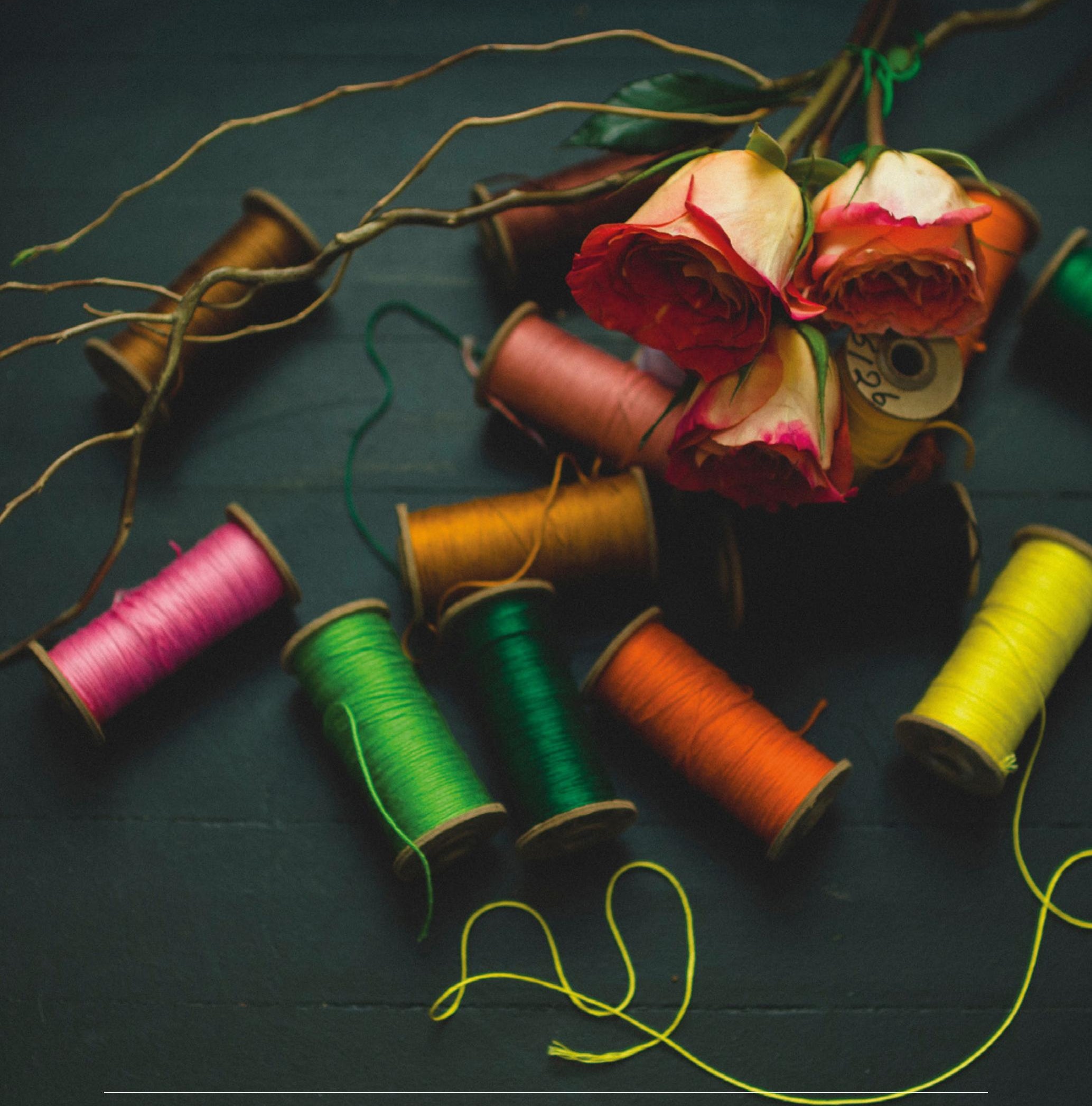


- "It will give people more visibility over their wardrobe and it will stop people buying as much as rapidly. And if they do buy they might be more conscious about buying staple pieces and things that have a bit more length to them especially when they see how much they spend on clothes."

- "I feel like they have helped people to manage and see what they have, and able to make informed decisions of if they need it, if they don't need it."

\subsection{A holistic solution}

App providing a consumercentric solution with complimentary services to help the entirety of the wardrobe management process.
- "I would hope that it would understand or learn my sense of style, so that by using it for a while, it would get a better idea of what I like and, therefore, it would hopefully get smarter and make better and better suggestions about what I should or could wear and just one less thing to think about, it's quite nice. Boom, here are some ideas, as opposed to me standing in front of my wardrobe"

- "For me it's really an app that brings together a lot of different elements, and instead of going pretty much everywhere, so say to a shop, to dry cleaning, to clothing consultants, to online or everything, the app that brings together all these types of services, depending on what the client wants. It could fit together the different outfits that you have in your wardrobe. It could be just to find a different service around you about a drycleaner or repairing your shoes and everything, it would be in one place."

- "I think it helps you manage your wardrobe and also to kind of in an ethical way as in the ethical underlining to that is if you manage your wardrobe better then you are going to need less clothes and it can also help you keep your wardrobe over time. So help you source services that can help you maintain your wardrobe and things like that."

- "It fits with the values that I have and also it helps me save time, and time is money you know! So like I think I would be willing to pay even for that sort of service if I knew that it was a service that would help me save time basically."

- "I already am mindful about my shopping choices, and so I think it would help me in terms of the inspiration and the making the most of what I already have. I think I'm pretty, I give serious thought to my clothing, like my shopping choices by enlarge. I suppose l'd be interested to see whether it would help me shop less because I would be getting more from my wardrobe. So I mean I have like I was saying, I love shopping, so would getting more out of my wardrobe counterbalance that love for shopping."

\subsection{A mindset shift}

Consumers focus on becoming more mindful and sustainable in their clothing consumption.
- "I think we should have a mindful approach to purchasing, consuming and disposing of clothing. So, that is, we really need to make conscious decisions when we do these activities. And I think a mindful approach is what's needed. You just need to ask yourself, in the moment, real questions, do I need it? Is it necessary? Is it going to add any anything to me? Is it good value? Is it going to last? You know, it's not an impulsive, mindless decision. So, it's basically bringing awareness to the experience of buying and consuming clothing."

- "It encourages, using what you have and maximising and optimising that, I think that takes the sustainability piece quite nicely because you're not encouraging buying more, getting more, spending money and feeding pointless purchasing that many people do. That's a great thing. That's something that would really, really help from a sustainability perspective. And yes, just being mindful of what you have and really optimising it and using as much as possible in creative ways with new outfit ideas that's also good.

- "It is being mindful in what you are buying. If you already have the equivalent in your house why are you buying it? Mindful of the budget and understanding that if what you are buying is not really needed maybe you could spend money on what would be better for everyone. Mindful of where the 
clothes are coming from, who is producing them, who is creating them. Mindful with your own wardrobe and making sure that you don't have too many clothes for nothing."

- "For me mindfulness is really more sustainability and being more aware about what we do as humans as well as a society and the impact it might have somewhere else where we tend to not want to know."

- "It means to be aware of what you have in your wardrobe and to be aware of what you can do with it, what you can't do and how it can be improved or changed. So yeah, and be aware of the brands that form your wardrobe. So be aware of like what the brands are doing and why they are doing it, and where you can find other brands that would suit you better. So it's just being really aware of your wardrobe."

- "It is about being more conscious about your decision making or more thoughtful about your decision making, and to some extent I suppose that means taking a step back and maybe looking at why you make the decisions you make."

- "It is easy to just be on this conveyor belt of fashion, of outside influences saying, making us think you know, well these are the latest trends and you have to shop them and you're going to a new event, you're going to a big event so you need to buy something new and you need to... If you are part of the generation who have been seen once on Instagram wearing this, therefore, never wear it again, I think there's this very conveyor belt approach to dressing and fashion and that if we were all more... If we all took a step back from that and we were able to make more mindful choices about it, I would be interested to see what would happen."

- "I think mindful is like you say the word and it is actually being mindful of your actions and knowing what you are doing and why you are doing it, not just reacting to an impulse. It is like going back to knowing who is behind your clothes, who made it, where it is coming from, how it was produced and just like reconnecting with that piece."

- "I think it is not just about consumption, mindfulness in general is in my area of work you have to make decisions all the time. And I think a mindful way of living helps in making decisions so you are thinking everything in a slightly different way, not short term but you are thinking long term."

- "I guess I am mindful in the way of being mindful of your actions, in that I would want to be mindful of not adding more clothes to landfill, of not buying clothes in shops where they don't pay living wages to their workers, that kind of thing"

- "For me mindfulness is about being in the moment so not worrying about what's coming down the line, not worrying about what's happened previously, it's about being aware that you know I can hear the sound of that person walking and I'm aware of my breath and that kind of thing so for me mindfulness is being present."

- "I think it's good to go back to maybe the essentials and just try to be happy with what you have and enjoy what you have, and not enjoy what you might have, and just be aware of that. And if everyone can pay attention about that, we wouldn't need to produce all the clothes we do, all the clothes we burn every year because they haven't been sold... trying to sustain everything, and we would have maybe a better wage consequences. It's like the butterfly effect in a way... it is really more sustainability thinking and being more aware about what we do as humans, as well as a society and the impact it might have somewhere else where we tend to not want to know."

- I think mindfulness a lot of the time is used for self-care but I think mindfulness is also being mindful of your actions and what the repercussions of that are, for instance, on the planet in terms of how you consume things. Also like how is this going to make other people feel, just being careful about things. 


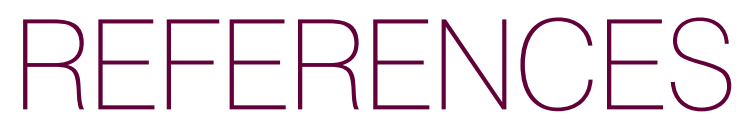

Amel, E. L., Manning, C. M., \& Scott, B. A. (2009).

Mindfulness and sustainable behavior: Pondering attention and awareness as means for increasing green behavior

Ecopsychology, 1(1), 14-25.

Brown, K. W., \& Kasser, T. (2005).

Are psychological and ecological well-being compatible? The role of values, mindfulness, and lifestyle.

Social Indicators Research, 74(2), 349-368.

Elle Magazine (2018). Editor's Letter, September, 49-50.

Fuentes, C., \& Sörum, N. (2019).

Agencing ethical consumers: smartphone apps and the socio-material reconfiguration of everyday life.

Consumption Markets \& Culture, 22(2), 131-156.

Hassan, L. M., Shiu, E., \& Shaw, D. (2016).

Who says there is an intention-behaviour gap? Assessing the empirical evidence of an intention-behaviour gap in ethical consumption.

Journal of Business Ethics, 136(2), 219-236.

Jackson, T. (2013).

Angst essen Seele auf - Escaping the 'iron cage' of consumerism.

Wuppertal Spezial, 48, 53-68.

Kabat Zinn, J. (2003).

Mindfulness-based interventions in context: past, present, and future. Clinical psychology:

Science and Practice, 10(2), 144-156.

McKinsey's State of Fashion Report (2018).

The State of Fashion 2019: A year of awakening, available online:

www.mckinsey.com/industries/retail/our-insights/the-state-of-fashion-2019-a-year-of-awakening

Sheth, J. N., Sethia, N. K., \& Srinivas, S. (2011).

Mindful consumption: a customer-centric approach to sustainability.

Journal of the Academy of Marketing Science, 39(1), 21-39.

Stanszus, L., Fischer, D., Böhme, T., Frank, P., Fritzsche, J., Geiger, S., ... \& Schrader, U. (2017).

Education for sustainable consumption through mindfulness training: Development of a consumption-specific intervention. Journal of Teacher Education for Sustainability, 19(1), 5-21.

UK Parliament: House of Commons Environmental Audit Committee (2019).

Fixing fashion: clothing consumption and sustainability: Fashion: it shouldn't cost the earth, HC1952, February 2019.

Wiseman, E. (2019). Feel Better Now?

The Observer Magazine, 10 March, 8-13. 


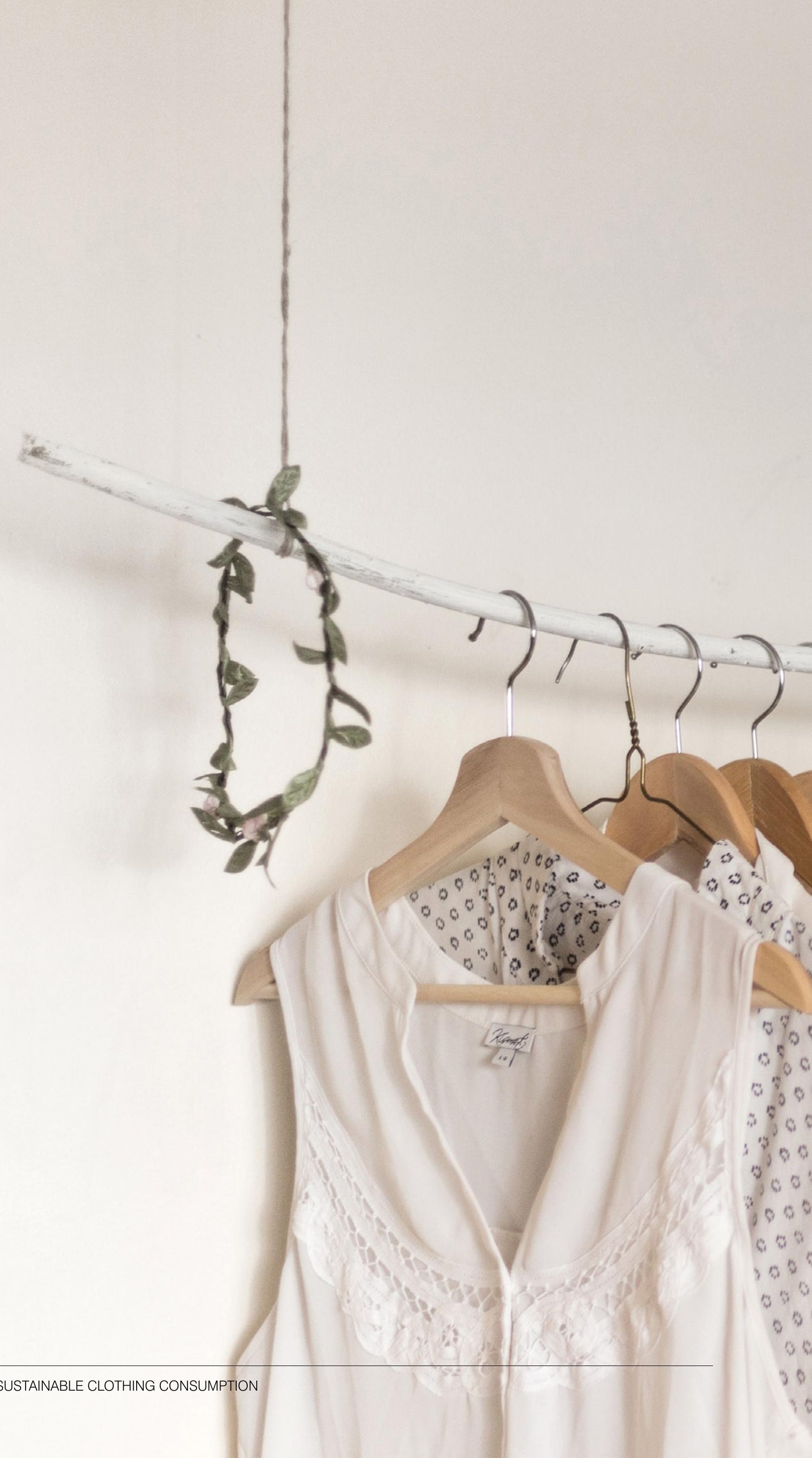




\section{FURTHER INFORMATION}

The findings in this report represent preliminary research which is now being taken forward into a larger scale study.

If you would like any further information on the current research and the work going forward, to discuss the research or to request hard copies of this report, please email the researchers:

\section{Katherine.duffy@glasgow.ac.uk Deirdre.shaw@glasgow.ac.uk}

glasgow.ac.uk/schools/business

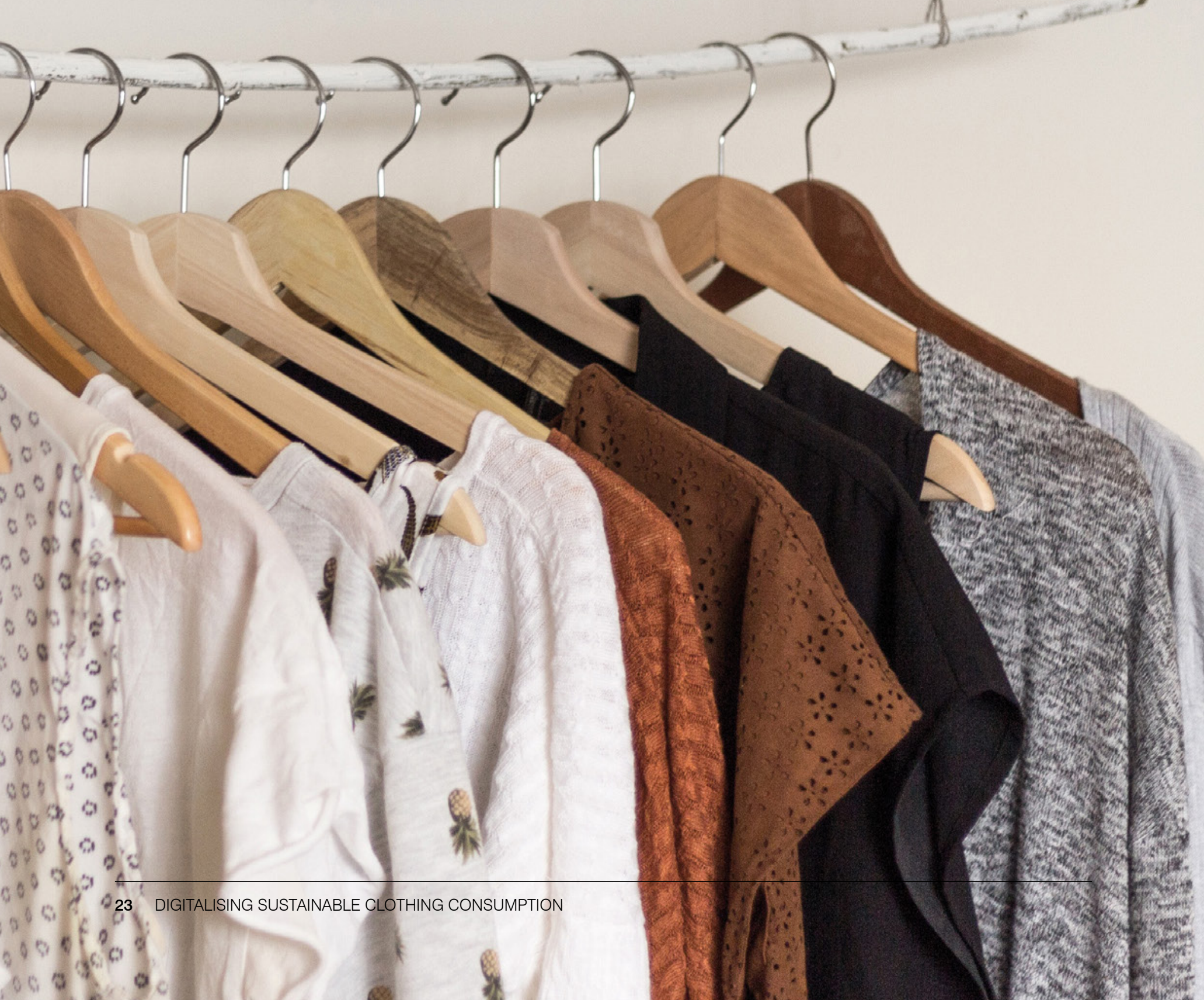


